\title{
Relação da expressão de fatores de crescimento celular (IGF-1) e (SCF) com fatores prognósticos e o alvo da rapamicina em mamíferos (m-TOR) em mastocitomas cutâneos caninos ${ }^{1}$
}

\author{
Raquel B. Ferioli ${ }^{2 *}$, Rafael Torres Neto², Sabrina S. Costa², Antonio C. Alessi, \\ Rafael M. Rocha ${ }^{5}$ e Renée Laufer Amorim²
}

\begin{abstract}
ABSTRAC.- Ferioli R.B., Torres Neto R., Costa S.S, Alessi A.C., Rocha R.M. \& Amorim R.L. 2013. [IGF-1 and SCF protein expression in cutaneous mast cell tumors in dogs and relation to prognostic factors and mammalian target of rapamycin (m-TOR).] Relação da expressão de fatores de crescimento cellular (IGF-1) e (SCF) com fatores prognósticos e o alvo da rapamicina em mamíferos (m-TOR) em mastocitomas cutâneos caninos. Pesquisa Veterinária Brasileira 33(4):549-556. Serviço de Patologia Veterinária, Faculdade de Medicina Veterinária e Zootecnia, Universidade Estadual Paulista Júlio de Mesquita Filho, Campus de Botucatu, Distrito de Rubião Jr s/n, Botucatu, SP 18618-970, Brazil. E-mail: raquel.ferioli@fmvz.unesp.br

Cutaneous mast cell tumor (MCT) is one of the most common neoplasms in the skin of dogs and express variable biological behavior. Among the MTC aspects studied, histological classification, proliferative index and protein expression of c-KIT show the most defined connection with the tumor prognostic. The aim of this study was to evaluate the protein expression of insulin-like growth factor type 1 (IGF-1), steam cell factor (SCF) and theit relationship with tyrosine kinase receptor (c-KIT), mammalian target of rapamycin (m-TOR), histological classification (KI-67), proliferative and mitotic index and epidemiological data in MTCs. In this study 133 MTC samples from 133 animals were used, arranged in tissue microarray (TMA) slides. The TMA was used for evaluation the proteins. An association was observed between SCF and histological grade proposed in 2011, mitotic index, cell proliferation, IGF-1, lesion site, age of the animals, and immunohistochemical pattern c-KIT receptor. The dependence relationship was also observed between IGF-1 and animal size, mitotic index, m-TOR and c-KIT. The SCF protein expression was related to canine MTCs aggressiveness, since it is more frequent in MCTs with c-KIT cytoplasmic. The relationship between the expression of IGF-1, SCF, c-KIT e m-TOR can be associated with the integration of its actions ways. The IGF-1 expression is associated with large dog breeds MTCs.
\end{abstract}

INDEX TERMS: Mast cell tumors, IGF-1, SCF, m-TOR, dogs.

\footnotetext{
${ }^{1}$ Recebido em 15 de outubro de 2012.

Aceito para publicação em 7 de março de 2013.

${ }^{2}$ Departamento de Clínica Veterinária, Faculdade de Medicina Veterinária e Zootecnia (FMVZ), Universidade Estadual Paulista (Unesp), Distrito de Rubião Júnior s/n, Cx.Postal 524, Botucatu, SP 18618-970, Brasil. *Autor para correspondência: raquel.ferioli@fmvz.unesp.br

${ }^{3}$ União Pioneira de Integração Social, Faculdade de Medicina Veterinaria e Zootecnia, Upis, Fazenda Lagoa Bonita, BR 20 Km 12, DF 335 Rural, Planaltina, G0 70340-000, Brasil.

${ }^{4}$ Departamento de Patologia Veterinária, Faculdade de Ciências Agrárias e Veterinárias de Jaboticabal (FCAV), Unesp, Via Paulo D. Castelane s/n, Jaboticabal, SP 14884-900, Brasil.

${ }^{5}$ Departamento Anatomia Patológica, Hospital do Câncer de São Paulo, Fundação Antônio Prudente, Rua Prof. Antônio Prudente 109, 1o andar, Liberdade, São Paulo, SP 01509-900, Brasil.
}

RESUMO-- O mastocitoma cutâneo (MTC) é a neoplasia maligna mais comum na pele dos cães e seu comportamento biológico é muito variável. Dentre os fatores prognósticos estudados nos MTCs, a classificação histopatológica, o índice proliferativo e o padrão de expressão doc-KIT são os que apresentam uma associação mais relevante com o provável prognóstico deste tumor. 0 objetivo deste trabalho foi avaliar a expressão proteica de fator de crescimento semelhante à insulina tipo 1 (IGF-1), fator de célula tronco (SCF) e sua relação com o receptor tirosina quinase (c-KIT), alvo da rapamicina em mamíferos (m-TOR), grau histológico, índice proliferativo pelo KI-67e o número de figuras de mitose (IM) com dados clínicos de cães com MTCs . Foram uti- 
lizadas 133 amostras de MTCs, provenientes de 133 cães, dispostas em lâminas de microarranjo de tecidos (TMA). A técnica de imuno-histoquímica foi utilizada para a avaliação destas proteínas. Observou-se associação entre SCF e, a graduação histopatológica proposta em 2011, índice mitótico, proliferação celular (KI-67), escore de IGF-1, local da lesão, idade dos animais e padrão imuno-histoquímico do receptor c-KIT. A relação de dependência também foi observada entre IGF-1 e o porte dos animais, IM, m-TOR e c-KIT. A expressão de SCF teve relacção com a agressividade dos MTCs caninos, uma vez que foi mais freqüente em MTCs com c-KIT citoplasmático. A relação entre a expressão de IGF-1, SCF, c-KIT e m-TOR pode estar associada à integralização de suas vias de ação. A expressão de IGF-1 está associada à MTCs em cães de porte grande.

TERMOS DE INDEXAÇÃO: Mastocitoma, IGF-1, SCF, m-TOR, caninos.

\section{INTRODUÇÃO}

O mastocitoma cutâneo (MTC) canino é uma neoplasia maligna constituída por mastócitos, que corresponde aproximadamente $11 \%$ das neoplasias cutâneas do cão e a mais comum na pele dos cães (Villamil et al. 2011). O comportamento biológico do MTC é muito variável, podendo ser um nódulo único, com a cura pela excisão cirúrgica até uma doença metastática fatal (Tham \& Vail 2007). Patnaik et al. (1984) propuseram uma classificação histopatológica em três graus de malignidade para os MTCs, que atualmente é o principal fator prognóstico, porém há discordância entre patologistas na graduação dos MTCs (Northrup et al. 2005, Pinczowski et al. 2008, Kiupel et al. 2011). Recentemente, uma nova classificação com dois graus de malignidade foi proposta (Kiupel et al. 2011) e parece trazer menor discordância, além de se correlacionar com o tempo de sobrevida.

0 grau histológico, idade, raça, sexo, localização e mutação no proto-oncogene KIT são fatores preditivos nos MTCs caninos (Tham \& Vail 2007). Outros fatores são o índice mitótico, proliferação celular (expressão proteica de Ki-67) e o padrão de expressão do c-KIT (Webster et al. 2004, Scase et al. 2006, Romansik et al. 2007).

Estudos indicam que, cerca de $15-40 \%$ dos MTCs contém mutações no gene KIT que codifica o receptor tirosina quinase c-KIT (Letard, et al. 2008, Welle et al. 2008). Seu ligante é o fator de célula tronco (SCF), conhecido também como fator de crescimento para mastócitos que é um fator de crescimento expresso em diversos tipos de tecidos (Linnekin, Jelacic, Shivakrupa 2003, Roskoski 2005).

Outro fator de crescimento importante no desenvolvimento de neoplasias é o IGF-1, que atua principalmente nas vias ativadora da mitose, da transcrição e inibidora da apoptose levando à proliferação celular (Levine et al. 2006, Samani et al. 2007). Suas ações são mediadas pelo receptor tirosina quinase IGF-1R (Ibrahim \& Yee 2004). Fosforilação do IGF-1R ou do receptor híbrido IGF-1R/IR-A pela ligação do IGF-1 ou IGF-2 predominantemente conduz à sinalização mitogênica (Belfiore et al. 2009).

Recentemente White et al. (2011) observaram que cães de raças de porte grande têm um risco maior de desenvolver MTC e as raças de porte pequeno têm um risco baixo.
Fatores de crescimento têm sido relacionados às neoplasias, como agentes para a manutenção da proliferação crônica e descontrolada, por diversos mecanismos (Neumann et al. 2007, Stoop et al. 2008, Yee \& Wood 2008, Callan \& Milne 2009, Hanahan \& Weinberg 2011, Werner 2011). 0 uso da tecnologia de arranjo em matriz tecidual (TMA - tissue microarray) que permite uma aceleração dos estudos associando achados moleculares in situ com informações clínico patológicas (Bubendorf et al. 2001) foi utilizada também no estudo dos MTCs (Webster et al. 2006).

A expressão do IGF-1 em cães até agora foi pouco estudada, principalmente em doenças como neoplasias. Devido à via sinalizadora do m-TOR ser estritamente associada com funções celulares, esta proteína desempenha um papel fundamental no desenvolvimento de algumas neoplasias em humanos (Albanell et al. 2007). 0 objetivo deste estudo foi investigar a expressão dos fatores de crescimento SCF e IGF-1 em MTCs e a sua relação com o grau histológico de acordo com Patnaik et al. (1984) e Kiupel et al. (2011), índice mitótico (IM) e com expressão proteica pela técnica de imuno-histoquímica (IHQ) de KI-67, m-TOR e receptor tirosina quinase (c-KIT).

\section{MATERIAL E MÉTODOS}

Seleção dos casos e elaboração da plataforma de arranjo de matriz tecidual

Este trabalho foi realizado de acordo com o termo de "Princípios Éticos na Experimentação Animal" tendo sido aprovado pela Comissão de Ética no Uso de Animais (CEUA) da Faculdade de Medicina Veterinária e Zootecnia (FMVZ), Unesp-Botucatu.

Foram selecionadas 133 amostras de MTCs, provenientes de 133 cães, dos arquivos dos Serviços de Patologia Veterinária da FMVZ (Botucatu/SP) e FCAV (Jaboticabal/SP), Unesp. 0 estudo retrospectivo incluiu amostras obtidas entre os anos de 2001 a 2010. Os blocos de parafina foram selecionados, novas lâminas histopatológicas foram confeccionadas, coradas por HE e revistas por três patologistas para confirmar o diagnóstico histopatológico de MTC e classificá-los de acordo com Patnaik et al. (1984) e Kiupel et al. (2011). Somente foram utilizados tumores primários cutâneos de animais que não receberam qualquer tipo de tratamento antitumoral antes da colheita da amostra.

Para construir os blocos de TMA, foram selecionadas as áreas representativas do grau histológico atribuído e com maior número de figuras de mitose para obtenção de um core de cada tumor. Utilizou-se o dispositivo manual Tissue Microarrayer (Beecher Instruments ${ }^{\circledR}$, EUA) para confecção de dois blocos receptores, um contendo amostras provenientes da FCAV, Jaboticabal (23 cores) e o outro da FMVZ, Unesp, Botucatu (110 cores). Os cores medindo $1 \mathrm{~mm}$ de diâmetro dos blocos doadores foram dispostos, com espaçamento de $0.2 \mathrm{~mm}$ entre eles, nos blocos receptores.Cortes de $3 \mu \mathrm{m}$ de espessura foram realizados consecutivamente e montados em lâminas adesivadas para este fim (Instrumedics Inc. ${ }^{\text {TM }}$, EUA). A primeira lâmina de cada TMA foi foi corada por HE, para confirmar a presença das áreas tumorais, as demais foram mergulhadas em parafina e acondicionadas a $-20^{\circ} \mathrm{C}$ até a realização da técnica de IHQ.

\section{Dados clínicos}

Para a obtenção das informações clínicas, como raça, sexo, idade, peso do animal e localização anatômica do tumor, foram realizadas consultas aos prontuários dos pacientes, chamadas telefônicas aos proprietários e aos médicos veterinários responsáveis pelos casos. 0 peso e porte foram categorizados de maneira a formar quatro grupos de acordo com White et al., (2011), sen- 
do: porte pequeno $(<9 \mathrm{~kg})$, porte médio $(9-18 \mathrm{~kg})$, porte grande $(18 \geq 36 \mathrm{~kg})$ e porte gigante $(>36 \mathrm{~kg})$. A idade dos animais também foi analisada por categorias, estabelecidas de acordo com White et al. (2011), em jovem ( $<5$ anos) meia idade (5-11 anos) e idoso (>11 anos). A localização anatômica foi dividida em: cabeça, tronco, membros, região perineal, escroto, vulva, e cauda.

\section{Classificação histopatológica e IM}

Com as lâminas originais coradas pela técnica de HE foram realizadas as classificações histopatológicas de acordo com Patnaik et al. (1984) e Kiupel et al. (2011) e a determinação do índice mitótico, feita seguindo os critérios de Romansik et al. (2007).

Avaliação da expressão proteica pela técnica de imuno-histoquímica em microarranjo de tecidos

As lâminas de TMA foram desparafinizadas em estufa $56^{\circ} \mathrm{C}$ por 24 horas e posteriormente colocadas em xilol e re-hidratados em álcool etílico em concentrações decrescentes e água deionizada. A recuperação antigênica foi realizada com tampão citrato $10 \mathrm{mM}, \mathrm{pH}$ 6,0, em câmara de pressão controlada (Pascal ${ }^{\circledR} /$ Dako, $^{2}$

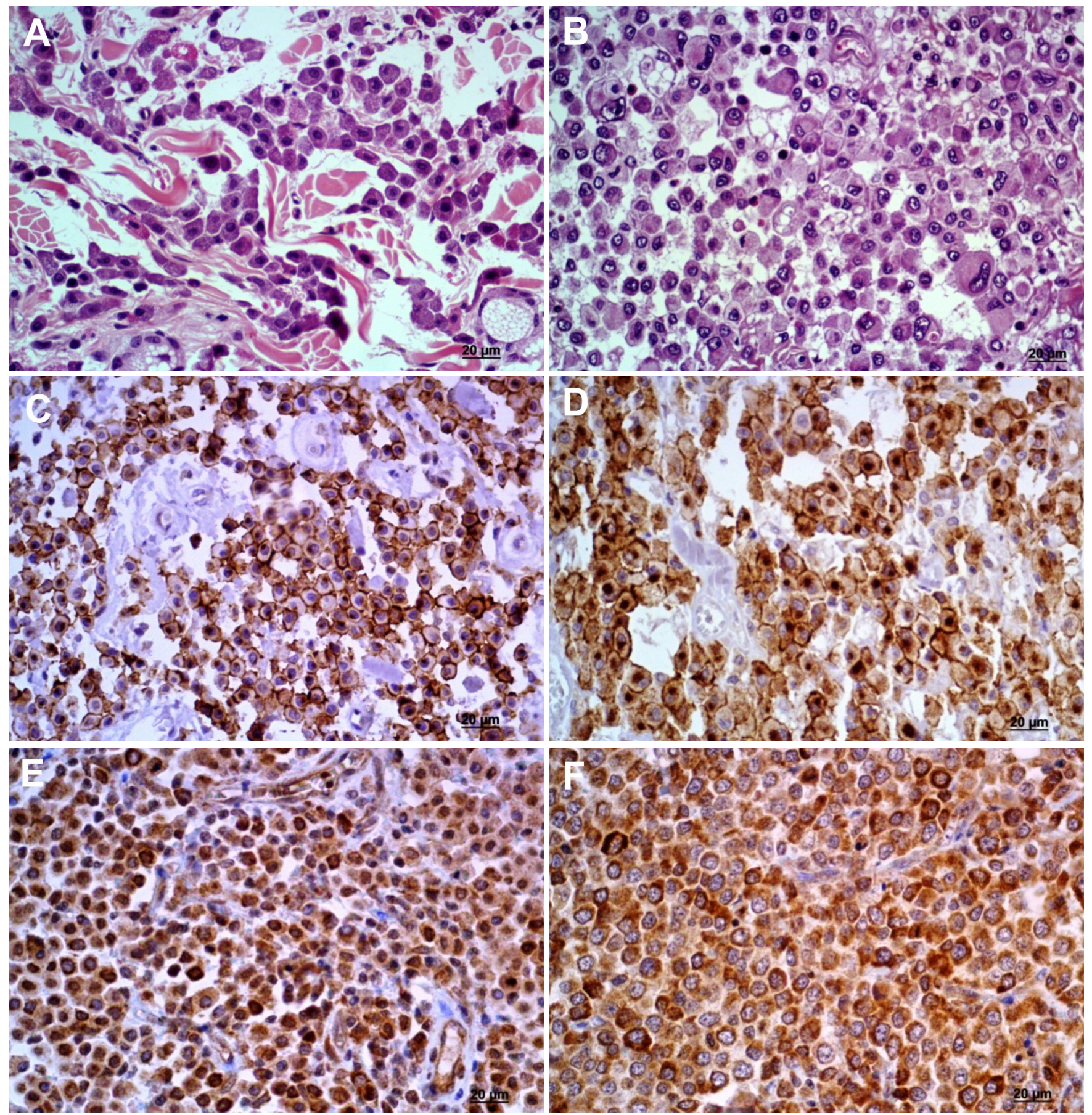

Fig.1. Mastocitoma cutâneo canino, na coluna das esquerda amostras classificadas como de baixo grau de malignidade e na coluna da direita de alto grau de malignidade, de acordo com Kiupel et al. (2011) em aumento de (400x), barra de 20 $\mu$ m. (A,B) Coloração de hematoxilina e eosina. (C,D) Expressãodo anticorpo anti-CD117 (c-KIT) padrão membranoso e citoplasmático focal. (E,F) Expressão do anticorpo anti-SCF. 
EUA) para os anticorpos c-KIT, KI-67, SCF, e IGF-1, para o anticorpo m-TOR utilizou-se o mesmo tampão no entanto em micro-ondas (Continental AW-4202A, potência máxima 900W) em dois ciclos de 5 minutos cada Em seguida, as lâminas foram resfriadas e lavadas em água deionizada.

Seguiu-se com a incubação em peróxido de hidrogêneo a 3\% em álcool metílico) durante 20 minutos, as lâminas foram lavadas em água deionizada e incubadas em tampão TRIS, pH 7,4, por 10 minutos. Os cortes foram submetidos ao bloqueio de proteínas inespecíficas com caseína a 3\% (Leite Molico ${ }^{\circledR}$, Nestlè) durante 1 hora a $27^{\circ} \mathrm{C}$, e aplicou-se em cada lâmina o anticorpo primário, levando à incubação durante 18 horas (overnight) em câmara úmida a $4^{\circ} \mathrm{C}$.

As lâminas foram lavadas duas vezes com tampão TRIS pH7,4, por incubadas com sistema de polímero (Advance ${ }^{\mathrm{TM}}$, Dako) de acordo com recomendações do fabricante, a $27^{\circ} \mathrm{C}$ e lavadas com TRIS. A coloração foi obtida utilizando-se solução pronta para uso de DAB (3,3' diaminobenzidinetetrachloride- Dako, EUA) por 3 minutos. Os cortes foram contra-corados com Hematoxilina de Mayer e desidratados em concentrações crescentes de álcool e xilol. Em seguida, as lâminas foram montadas com resina e lamínula.

Como controle negativo, a incubação do anticorpo primário foi substituída por soro não imune (imunoglobulina de camundongo ou coelho, Dako, EUA) em lâmina com corte de MTC e como controle positivo foi utilizada lâmina com de tecido de cão, escolhido de acordo com as indicações do fabricante de cada anticorpo primário e que sabidamente reagia com cada anticorpo primário (Quadro 1). Todas as reações de controle positivo ou negativo foram feitas concomitantemente às lâminas do TMA.

Quadro 1. Descrição dos anticorpos primários utilizados na técnica de imunoistoquímica, fabricante, clone, controle positivo, diluição e padrão de expressão

\begin{tabular}{|c|c|c|c|c|c|}
\hline $\begin{array}{l}\text { Anticorpo } \\
\text { primário }\end{array}$ & Fabricante & Clone & $\begin{array}{c}\text { Controle } \\
\text { positivo cão }\end{array}$ & Diluição & Expressão \\
\hline $\begin{array}{l}\text { c-KIT } \\
\text { (CD117) }\end{array}$ & $\begin{array}{c}\text { Dako } \\
\text { Cytomation }\end{array}$ & Policlonal & $\begin{array}{l}\text { Mastócitos } \\
\text { Dermatite } \\
\text { alérgica }\end{array}$ & $1: 400$ & $\begin{array}{l}\text { Membrana/ } \\
\text { citoplasma }\end{array}$ \\
\hline Ki-67 & $\begin{array}{c}\text { Dako } \\
\text { Cytomation }\end{array}$ & MIB-1 & Linfonodo & $1: 50$ & Nuclear \\
\hline SCF & Santa Cruz & Policlonal & & $1: 50$ & \\
\hline & Neoma & & & & Citoplasma \\
\hline m-TOR & Millipore & Policlonal & Próstata & $1: 200$ & $\begin{array}{l}\text { Membrana/ } \\
\text { citoplasma }\end{array}$ \\
\hline
\end{tabular}

Para a análise da expressão proteica de cada anticorpo e para o registro das fotomicrografias, foi utilizado o programa de análise de imagens Leica Qwin versão 3.0, em microscópio óptico convencional (Leica - DMR, Alemanha), com câmera digital acoplada (Leica - DFC500, Alemanha). 0 padrão de expresão do c-KIT foi avaliado de acordo com Webster et al. (2004) em citoplasmático e membranoso (Fig.1C,D). As marcações citoplasmática focal e difusa foram agrupadas e compoem o grupo citoplasmático, tendo em vista que ambas estão associadas a prognóstico pior (Webster et al. 2004, Gil Da Costa et al. 2007). Na avaliação da proliferação celular as células com núcleos positivos para o KI-67, foram contadas em um campo de 400x, considerando-se como ponto de corte 23 células, conforme Webster et al. (2007). Só foram considerados os cores que tivessem pelo menos uma célula marcada para KI-67 e aqueles sem nenhuma célula positiva foram descartados do estudo. Para a avaliação da expressão de SCF, IGF-1 e m-TOR, analisou-se o percentual de células marcadas em cada core, classificando em escores de zero a quatro, sendo (0): negativo, (1): menos de $10 \%$ das células positivas; (2): $10 \geq 30 \%$ das células positivas; (3): $31 \geq 60 \%$ das células positivas; e (4): > $60 \%$ das células positivas. Para avaliação da intensidade de marcação das células que predominava em cada core utilizaram-se escores de um a três, sendo (1): fraca, (2): moderada; (3): forte.

\section{Análise estatística}

O teste de Qui-quadrado ou o teste exato de Fisher foram aplicados para avaliar a força de associação entre a expressão de SCF e IGF-1 e as graduações histopatológicas (Patnaik et al. 1984, Kiupel et al. 2011), índice mitótico (IM) (Romansik et al. 2007), e com a expressão proteica pela técnica de IHQ de KI-67 (para a proliferação celular), m-TOR, e receptor c-KIT. Os dados clínicos dos cães (raça, idade, gênero, porte, e local da lesão) também foram avaliados quanto às suas associações com a expressão proteica do IGF-1, m-TOR, SCF e c-KIT. Para todas as análises estatísticas foi considerado o nível de significância de $5 \%$ e o programa utilizado foi o SAS System versão 9.2.

\section{RESULTADOS}

Das 133 amostras de MTC canino avaliadas pela classificação histopatológica descrita por Patnaik et al. (1984), 13 (10\%) foram classificadas como grau 1, 88 (66\%) como grau 2 e 32 (24\%) como grau 3. De acordo com a descrição histopatológica feita por Kiupel et al. (2011), 34 (26\%) foram classificados como de alto grau de malignidade e 99 (74\%) como de baixo grau de malignidade (Fig.1A,B). Na avaliação do índice mitótico, 89\% (118/133) dos MTCs caninos tinham até 5 figuras de mitose em 10 campos (400x) e $11 \%(15 / 133)$ tinham mais do que 5 figuras de mitose.

Quanto aos dados clinicos, registrou-se: raça (130/133 MTCs), sexo (119/133 MTCs), idade (92/133 MTCs), peso (128/133 MTCs) e localização (81/133 MTCs), 52\% (62/119) dos animais eram fêmeas e 48\% (57/119) machos, o peso dos animais variou entre 4 e $72 \mathrm{~kg}, 10 \%$ $(13 / 128)$ eram de porte pequeno, $5 \%(7 / 128)$ de porte médio, 79\% (100/128) de porte grande e $6 \%(8 / 128)$ de porte gigante. A idade dos animais variou entre 1,5 e 13 anos, sendo $22 \%$ (20/92) cães jovens; $70 \%$ (65/92) cães de meia idade e $8 \%$ (7/92) cães idosos.

Pela técnica de imunoistoquímica foi possível avaliar a proliferação celular pela proteína KI-67, sendo que 86\% $(114 / 133)$ dos casos apresentaram até 23 células que expressaram KI-67 e 14\% (19/133) dos casos apresentaram mais do que 23 células.

\section{Avaliação do fator de célula tronco}

Neste estudo a expressão de SCF em MTCs caninos foi observada em 100\% (133/133) dos casos avaliados (Fig.1E,F) tanto em mastócitos quanto fibroblastos e células endoteliais dos vasos. Observamos a associação entre o escore de marcação do SCF (todos os casos receberam o escore 4: >60\% das células positivas) e o padrão de expressão de c-KIT (Fig.D,E) $(p<0,00001)$, sendo que $70 \%$ das amostras apresentaram o padrão de expressão de c-KIT citoplasmático.

Houve relação entre a intensidade de marcação do SCF e índice mitótico $(\mathrm{p}=0,0071)$ sendo que $89 \%$ das amostras tinham IM menor ou igual a 5 figuras de mitose, destas $45 \%$ receberam escore de intensidade de marcação como moderado. 
Em relação às classificações histopatológicas, houve associação apenas com a classificação proposta por Kiupel et al. (2011), tanto para a intensidade de marcação do SCF $(p=0,0071)$ quanto para o escore de marcação do SCF ( $p<$ $0,0001)$, a maioria dos MTCs caninos eram de baixo grau (74\%) e apresentaram intensidade de marcação fraca e moderada ( $44 \%$ e $43 \%$ respectivamente).

$\mathrm{Na}$ avaliação de SCF em relação aos dados clínicos, houve associação com a localização anatômica dos MTCs $(\mathrm{p}<0,0001)$, sendo que 43\% (56/133) dos tumores localizavam-se no tronco e membros dos animais, destes $45 \%$ apresentavam intensidade de marcação fraca e $37 \%$ moderada. Observou-se também, associação entre o escore de marcação e a idade categorizada $(\mathrm{p}<0,0001)$. Das amostras com intensidade de marcação fraca, 68\% (25/37) eram de cães de meia idade $(\mathrm{p}<0,0001)$ e das amostras com intensidade de marcação moderada $74 \%$ (26/35) eram de cães de meia idade $(\mathrm{p}<0,0001)$.

\section{Avaliação do fator de crescimento semelhante à insuli- na tipo 1 (IGF-1)}

A expressão do fator de crescimento IGF-1 foi avaliada, e 94\% (118/125) dos casos foram positivos pela técnica de IHQ. Destes, 58\% (69/118) receberam o escore 4 (> 60\% das células marcadas) (Fig. 2H) e 52\% (61/118) a intensidade de marcação fraca.

A associação entre IGF-1 e o padrão de marcação do c-KIT foi observada para o escore de marcação, dos casos com c-KIT citoplasmático (88/125), 65\% (57/88) receberam o escore 4 para IGF-1, $(\mathrm{p}=0,0012)$. Observou-se também associação da intensidade de marcação de IGF-1 e o padrão citoplasmático do c-KIT $(\mathrm{p}=0,0050)$ com distribuição igualitária de $43 \%$ (38/88) tanto para intensidade fraca quanto para a moderada (Fig.2H).

Em relação ao SCF, observamos a associação da intensidade de marcação do SCF com a expressão de IGF-1, tanto na avaliação por escore de marcação quanto por intensidade de marcação ( $p=0,0405$ e $p=0,0153$ ) respectivamente.

A intensidade de marcação do m-TOR, se associou com a intensidade de marcação do IGF-1 ( $p<0,0001$ ) com 92\% $(114 / 124)$ dos casos sendo positivos para os dois marcadores (Fig.2G,H,I), destes 19\% (24/124) apresentaram a combinação de marcação fraca para IGF-1 e moderada para m.-TOR. Foi observada também associação do escore de marcação de IGF-1 com a intensidade de marcação do m-TOR (p=0,0083), 29\% (33/114) com a combinação de escore 4 para IGF-1 e intensidade moderada para o m-TOR (Fig.2J).
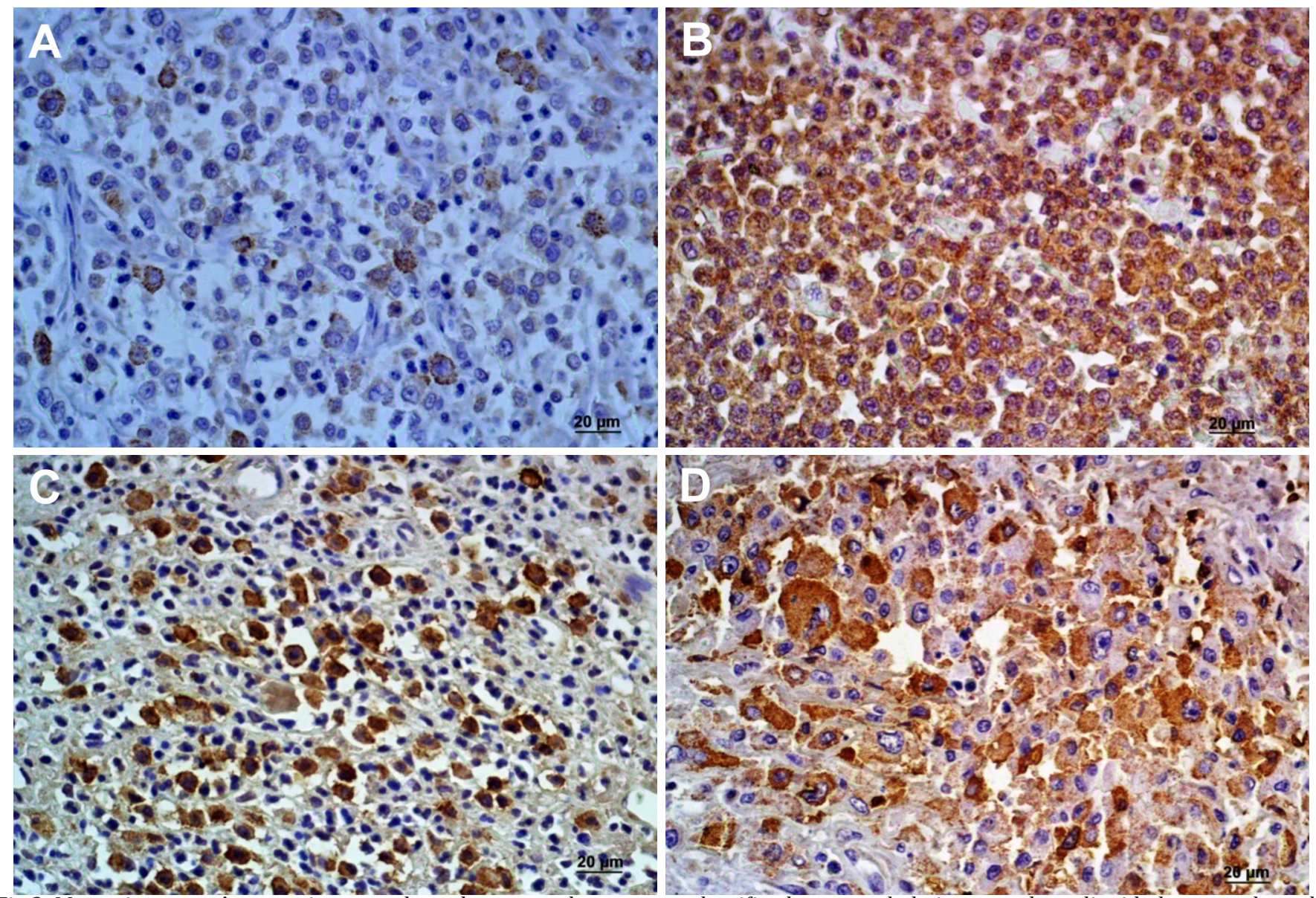

Fig.2. Mastocitoma cutâneo canino, na coluna das esquerda amostras classificadas como de baixo grau de malignidade e na coluna da

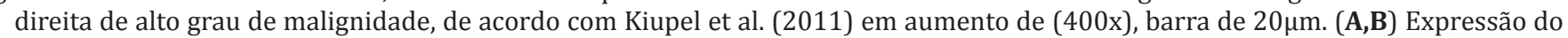
anticorpo anti-IGF-1 alguns mastócitos marcados fortemente e marcação moderada e difusa. (C,D) Expressão do anticorpo anti-m-TOR marcação forte e moderada. 
Quando foi avaliada a relação entre a expressão de IGF1 e os fatores prognósticos analisados, observou-se a associação entre o escore de marcação e o índice mitótico $(\mathrm{p}=0,0021)$, sendo que $55 \%$ dos casos $(69 / 125)$ receberam escore 4 e destes $94 \%(65 / 69)$ tiveram IM até 5 figuras de mitose. A relação de dependência entre a distribuição da intensidade de marcação do IGF-1 (118 amostras), segundo o porte categorizado dos animais (128 amostras) foi significativa $(\mathrm{p}=0,0334)$ com $36 \%(43 / 118)$ dos cães sendo de porte grande e com intensidade de marcação fraca. Além disso, todas as amostras com intensidade de marcação forte eram de cães de porte grande (14/118).

\section{DISCUSSÃO}

A expressão proteica de SCF foi observada em todas as amostras avaliadas, com mais de $60 \%$ das células neoplásicas marcadas. Não há relatos na literatura sobre o papel deste fator de crescimento em MTCs caninos. Takeuchi et al. (2010) determinaram a expressão de SCF em uma linhagem de mastócitos neoplásicos de cães com o uso da técnica de Western blotting, e observaram que a fosforilação do receptor c-KIT pode ser causada pela via de estimulação autócrina do SCF em mastócitos que tenham mutações funcionais no gene KIT.

Em nosso trabalho não foi possível determinar qual a isoforma do SCF (solúvel ou ancorada à membrana) foi expressa nas amostras avaliadas, pois o anticorpo utilizado detecta ambas as formas. No entanto não observamos a expressão do SCF no meio extracelular que circundava os mastócitos nos MTCs caninos analisados, exceto em células endoteliais de vasos sanguíneos e fibroblastos. 0 que poderia nos levar a inferir que a maior parte do SCF expresso nos MTCs caninos que avaliamos seja a isoforma ancorada à membrana $\left(\mathrm{SCF}_{\mathrm{m}}\right)$. Ambas as formas do SCF são biologicamente ativas com funções distintas, bem como com sobreposição de funções, SCFm induz ativação do receptor c-KIT mais persistente do que SCF solúvel (Linnekin, Jelacic, Shivakrupa 2003). É provável que a internalização do receptor c-KIT ocorra após a sua ligação com o SCFm. Estes fatos explicariam a associação entre a expressão do SCF e o padrão de expressão citoplasmática do c-KIT, observado em nosso trabalho.

A expressão de SCF foi associada à proliferação celular e ao índice mitótico quando se avaliou a sua intensidade de marcação. A maioria dos casos (86\%) teve um índice mitótico menor ou igual a 5 figuras de mitose e a proliferação celular avaliada pela proteína KI-67 comportou-se da mesma maneira, com a maior parte das amostras (65\%) com contagem até 7 células positivas. Observamos que a intensidade de marcação do SCF está inversamente associada à proliferação celular no MTC. A associação observada entre a expressão de SCF e a graduação histopatológica proposta por Kiupel et al. (2011), teve a maioria dos MCTS como de baixo grau de malignidade, o que corrobora com os achados observados em relação ao IM e a proliferação celular em nosso trabalho, tendo em vista que MTCs de baixo grau apresentam um índice de proliferação celular menor (Kiupel et al. 2011). A divisão e a proliferação celular envolvem múltiplas proteínas que ativam e inibem estes processos, os tecidos normais controlam a produção e liberação de sinais promotores de crescimento que coordenam a entrada e a progressão da célula no ciclo de divisão celular (Hanahn \& Weinberg 2011).

Uma hipótese para a associação observada entre a expressão de SCF e a menor proliferação celular nos MTCs caninos é a atuação deste fator de crescimento em mastócitos normais, sua ligação com o c-KIT é necessária para o crescimento e proliferação destas células, o que poderia explicar a expressão maior de SCF em MTCs caninos bem diferenciados, porém com controle da fosforilação deste receptor tirosina quinase, ao contrário do que poderia ser observado na localização citoplasmática de c-KIT.

A localização anatômica dos MTCs foi relacionada à expressão de SCF na avaliação por escore de marcação, sendo que $43 \%$ dos casos localizavam-se em tronco e membros. De todos os casos avaliados $40 \%$ estavam localizados no tronco e, somados, tronco e membros representaram $68 \%$. 0 mastocitoma ocorre em todo o organismo, mas no tegumento os locais de maior ocorrência são o tronco e extremidades (Kiupel et al. 2005, Thamm \& Vail 2007). Brøden et al. (2010) também observaram em seu trabalho que $40 \%$ dos MTCs localizaram-se em tronco. Ainda não há uma explicação para esse fato. Uma das razões para a prevalência do MTCs em tronco e membros poderia ser a proporção entre os diferentes níveis de expressão das isoformas do SCF nestas localizações anatômicas. Quarenta por cento dos casos apresentaram intensidade de marcação moderada (53/133) e $20 \%(26 / 133)$ apresentaram intensidade de marcação forte, destes obtivemos a informação da localização do tumor em 53\% (14/26), sendo a maioria em tronco e membros 64\% (9/14). Essa expressão mais forte do SCF poderia explicar a prevalência maior dos MTCs em troncos e membros. Outra hipótese seria a maior proporção de fibroblastos nestas regiões, que tem a derme mais espessa em relação ao restante do corpo (Scott 2001). Os trabalhos de Kitamura et al. (1989), Fujita et al. (1989) e Jarboe \& Huff (1989) relataram evidências biológicas fortes de que fibroblastos podem produzir as isoformas $\mathrm{SCF}_{\mathrm{m}}$ e $\mathrm{SCF}_{\mathrm{s}}$.

A idade em categorias também foi relacionada à expressão de SCF, com predomínio em cães de meia idade (5 -11 anos) com maior expressão de SCF. Este achado pode contribuir para o fato de que o MTC ocorre mais frequentemente em animais com média de idade de nove anos (Thamm \& Vail 2007).

A expressão de IGF-1 nos MTCs caninos foi de $94 \%$ de positividade. Embora estudo prévio tenha identificado a relação entre os níveis séricos de IGF-1 e o porte em várias raças de cães (Eigenmann, Amador, Patterson 1988) e tenham sido relacionados ao crescimento em humanos (Froesch et al. 1963, Daughaday et al. 1972) o fato que deve ser lembrado é que, são os valores teciduais e não os séricos de IGF-1 que determinam o crescimento do corpo (Yakar et al. 1999).

A associação entre a expressão de IGF-1 e SCF foi observada no nosso trabalho. McNiece \& Briddel (1995) descreveram a ação sinérgica entre SCF e outros fatores de crescimento. Uma possibilidade seria o SCF atuar na mobilização de mastócitos, para o local onde ele está sendo 
secretado em quantidade maior por fibroblastos e pelos próprios mastócitos e o IGF-1 atuar no crescimento, proliferação e diferenciação destes mastócitos. Isso explicaria a co-expressão destes dois fatores e o fato de o SCF não estar associado à MTCs caninos com alto índice mitótico, além disso observamos que 49\% (61/125) dos MTCs apresentaram a intensidade de marcação fraca para o IGF-1, o que explicaria a prevalência de MTCs mais diferenciados.

As expressões de IGF-1 e m-TOR foram observadas simultaneamente em $92 \%$ das amostras de MTCs caninos analisados. As funções do m-TOR que são mais bem entendidas em células de mamíferos estão relacionadas ao controle da transcrição e tradução do RNA mensageiro, síntese biogênese ribossomal, autofagia e controle do tamanho celular (Albanell et al. 2007). Rebuzzi et al. (2007) descreveram em MTCs caninos, o envolvimento da via do m-TOR/ PI3K na via de sinalização do VEGF, que por sua vez estimula a neovascularização e a sobrevida das células neoplásicas. $\mathrm{O}$ aumento de $\mathrm{m}$-TOR poderia se relacionar à angiogênese nos MTCs estudados, ligada a maior sobrevida dos mastócitos e talvez um controle de entrada no ciclo celular. Uma vez que o m-TOR está envolvido na expressão gênica e proteica da célula, o aumento concomitante de IGF-1 e m-TOR se complementam e asseguram o crescimento celular dos MCTs caninos.

As análises feitas relacionando a expressão de IGF-1 e os fatores prognósticos analisados determinaram a associação entre o escore de marcação do IGF-1 e o índice mitótico. O IGF-1 é um importante fator mitogênico devido ao seu papel na promoção da diferenciação somática (Annunziata, Granata, Ghigo 2011). A maior parte dos casos (88\%) apresentou até 5 figuras de mitose, mesmo com altos escores de expressão de IGF-1. Considerando o microambiente celular, os efeitos proliferativos do IGF-1 podem ser sucedidos por indução da diferenciação celular (Annunziata, Granata, Ghigo 2011), o que pode explicar estes achados, supondo-se que os mastócitos neoplásicos já se encontravam em fase de diferenciação e não de proliferação e somando-se a isso, observamos $74 \%$ de MTCs de baixo grau de malignidade, ou seja, tumores mais diferenciados.

Um dos achados mais interessantes deste trabalho foi a associação entre a expressão do fator de crescimento IGF-1 e o porte dos animais acometidos pelo MTC. Observamos que $82 \%$ dos casos que expressaram IGF-1 eram de cães de porte grande e gigante. Uma das hipóteses para explicar esta relação é a influência do gene IGF1 e a sua proteína expressa o fator de crescimento IGF-1. O gene IGF1 é um determinante genético forte do tamanho do corpo dos mamíferos, em cães um único alelo deste gene é o determinante para o porte na maioria das raças pequenas (Sutter et al. 2007). Sendo assim, o porte do animal poderia influenciar no surgimento dos MTCs caninos, ligados aos receptores do tipo tirosina quinase e seus ligantes, como é o caso do IGF-1. A expressão de IGF-1 em cães até agora foi pouco estudada, principalmente em doenças como neoplasias. A expressão deste fator foi avaliada em linhagens de células de osteossarcomas e tumor neuroendócrino de pâncreas, os níveis séricos maiores foram determinados em cães com tumores de mama e neoplasias hepáticas (Macewen et al.
2004, Neumann et al. 2007, Finotello et al. 2009, Queiroga et al. 2009).

A relação de dependência entre a expressão dos fatores de crescimento SCF e IGF-1 e os marcadores moleculares envolvidos em suas vias, c-KIT e m-TOR foi observada nos MTCs caninos avaliados. A expressão de SCF está envolvida no desenvolvimento do MTC canino e está associada à expressão de seu receptor celular c-KIT, fatores prognósticos como o grau histológico proposto por Kiupel et al. (2011), índice mitótico e proliferação celular, e dados clínicos como a localização anatômica da neoplasia e a idade dos animais acometidos. A co-expressão do fator IGF-1 foi demonstrada em MTCs caninos e se relacionou com a expressão de c-KIT, SCF e m-TOR, que pode ser explicada pela integralização das vias moleculares de ação dessas proteínas. Os diferentes padrões de expressão e associação destas proteínas, somados aos fatores prognósticos e dados clínicos podem refletir o comportamentos biológico variável do MTC canino.

Agradecimentos.- À Coordenação de Aperfeiçoamento de Pessoal de Nível Superior (CAPES) pela concessão de bolsa de estudos de mestrado, e a Fundação de Amparo à Pesquisa do Estado de São Paulo (Fapesp) pelo auxílio financeiro.

\section{REFERÊNCIAS}

Albanell J., Dalmases A., Rovira A. \& Rojo F. 2007. mTOR signalling in human cancer. Clinical and Translational Oncology 9:484-493.

Annunziata M., Granata R. \& Ghigo E. 2011. The IGF system. Acta Diabetologica 48(1):1-9.

Belfiore A., Frasca F., Pandini G., Sciacca L. \& Vigneri R. 2009. Insulin receptor isoforms and insulin receptor/insulin-like growth factor receptor hybrids in physiology and disease. Endocrine Reviews 30:586623.

Brønden L.B., Eriksen T. \& Kristensen A.T. 2010. Mast cell tumours and other skin neoplasia in Danish dogs: data from the Danish Veterinary Cancer Registry. Acta Vet. Scand. 52(6):1-6.

Bubendorf L., Nocito A., Holger M. \& Sauter G. 2001. Tissue microarray (TMA) technology: miniaturized pathology archives for high-throughput in situ studies. J. Pathol. 195:72-79.

Callan A.C. \& Milne E. 2009. Involvement of the IGF system in fetal growth and childhood cancer: An overview of potential mechanisms. Cancer Cause Control 20:1783-1798.

Daughaday W.H., Hall K., Raben M.S., Salmon Jr W.D., Van Den Brande J.L. \& Van Wyk J.J. 1972. Somatomedin: proposed designation for sulphation factor. Nature 235:107.

Eigenmann J.E., Amador A. \& Patterson D.F. 1988. Insulin-like growth factor I levels in proportionate dogs, chondrodystrophic dogs and in giant dogs. Acta Endocrinologica, Copenhagen, 118(1):105-108.

Finotello R., Marchetti V., Nesi G., Arvigo M., Baroni G., Vannozzi I. \& Minuto F. 2009. Pancreatic Islet Cell Tumor Secreting Insulin-Like Growth Factor Type-II in a Dog. J. Vet. Intern. Med. 23:1289-1292.

Froesch E.R., Buergi H., Ramseier E.B., Bally P. \& Labhart A. 1963. Antibody-suppressible and nonsuppressible insulin-like activities in human serum and their physiologic significance: an insulin assay with adipose tissue of increased precision and specificity. J. Clin. Invest. 42:18161834.

Fujita J., Onoue H., Ebi Y., Nakayama H. \& Kanakura Y. 1989. In vitro duplication and in vivo cure of mast-cell deficiency of SI/Sid mutant mice by cloned 3T3 fibroblasts. Proc. Natl Acad. Sci. USA 86:2888-2891.

Hanahan D. \& Weinberg, R.A. 2011. Hallmarks of cancer: The next generation. Cell 144: 646-674.

Ibrahim Y.H. \& Yee D. 2004. Insulin-like growth factor-I and cancer risk. Growth Hormone and IGF Res. 14:261-269. 
Jarboe D.L. \& Huff T.F. 1989. The mast cell-committed progenitor. II. W1W' mice do not make mast cell-committed progenitors and S//S/d fibroblasts do not support development of normal mast cell-committed progenitors. J. Immunol. 142:2418-2423.

Kitamura Y., Nakayama H. \& Fujita J. 1989. Mechanism of mast cell deficiency in mutant mice of W/WV" and SI/SI" genotype, p.15-25. In: Galli S.J. \& Austen K.F. (Eds), Mast Cell and Basophil Differentiation and Function in Health and Disease. Raven, New York.

Kiupel M., Webster J.D., Bailey K.L., Best S., Delay J., Detrisac C.J., Fitzgerald S.D., Gamble D., Ginn P.E., Goldschmidt M.H., Hendrick M.J., Howerth E.W., Janovitz E.B., Langohr I., Lenz S.D., Lipscomb T.P., Miller M.A., Misdorp W., Moroff S., Mullaney T.P., Neyens I., O'toole D., Ramos-Vara J., Scase T.J., Schulman F.Y., Sledge D., Smedley R.C., Smith K., Snyder P.W., Southorn E., Stedman N.L., Steficek B.A., Stromberg P.C., Valli V.E., Weisbrode S.E., Yager J., Heller J. \& Miller R. 2011. Proposal of a two-tier histologic grading system for canine cutaneous mast cell tumors to more accurately predict biological behavior. Vet. Pathol. 48:147-155.

Letard S., Yang Y., Hanssens K., Palmérini F., Leventhal P.S., Guéry S., Moussy A., Kinet P.P., Hermine O. \& Dubreuil P. 2008. Gain-of-function mutations in the extracellular domain of kit are common in canine mast cell tumors. Mol. Cancer Res. 6(7):1137-1144.

Levine A.J., Feng Z., Mak T.W., You H. \& Jin S. 2006. Coordination and communication between the p53 and IGF-1-AKT-TOR signal transduction pathways. Genes Development. 20:267-275.

Linnekin D., Jelacic T. \& Shivakrupa R. 2003. Stem cell factor, p.393-403. In: Henry H.L. \& Norman A.W. (Eds), Encyclopedia of Hormones. Academic Press, Maryland Heights.

London C.A., Galli S.J., Yuuki T., Hu Z.Q., Helfand S.C. \& Geissler E.N. 1999. Spontaneous canine mast cell tumors express tandem duplications in the proto-oncogene kit. Exp. Hematol. 27:689-697.

MacEwen E.G., Pastor J., Kutzke J., Tsan R., Kurzman I.D., Thamm D.H., Wilson M. \& Radinsky R. 2004. IGF-1 Receptor contributes to the malignant phenotype in human and canine osteosarcoma. J. Cell. Biochem. 92:7791.

McNiece I.K. \& Briddell R.A. 1995. Stem cell factor. J. Leucocyte Biol. 57:1422.

Northrup N.C., Howerth E.W., Harmon B.G., Brown C.A., Carmicheal K.P., Garcia A.P., Latimer K.S., Munday J.S., Rakich P.M., Richey L.J., Stedman N.L. \& Gieger T.L. 2005. Variation among pathologists in the histologic grading of canine cutaneous mast cell tumors with uniform use of a single grading reference. J. Vet. Diagn. Invest. 17:561-564.

Patnaik A.K., Ehler W.J. \& Macewen E.G. 1984. Canine cutaneous mast cell tumors: morphologic grading and survival time in 83 dogs. Vet. Pathol. 21:469-474.

Pinczowski P., Torres Neto R., Fabris V.E. \& Amorim R.L. 2008. Mastocitoma cutâneo canino: variação entre observadores na graduação histopatológica. Clín. Vet. 77:76-78.

Queiroga F.L., Pérez-Alenza D., Silvan G., Peña L., Lopes C.L. \& Illera J.C. 2010. Serum and intratumoural GH and IGF-I concentrations: Prognostic factors in the outcome of canine mammary cancer. Res. Vet. Sci. 89:396-403.

Rebuzzi L., Willmann M., Sonneck K., Gleixner K.V., Florian S., Kondo R., Mayerhofer M., Vales A., Gruze A., Pickl W.F., Thalhammer J.G. \& Valent P. 2007. Detection of vascular endothelial growth factor (VEGF) and VEGF receptors Flt-1 and KDR in canine mastocitoma cells. Vet. Immunol. Immunopathol. 115:320-333.

Romansik E.M., Reilly C.M., Kass P.H., Moore P.F. \& London P.F. 2007. Mitotic index is predictive for survival for canine cutaneous mast cell tumors. Vet. Pathol. 44:335-341.

Roskoski Jr R. 2005. Signaling by Kit protein-tyrosine kinase: The stem cell factor receptor. Biochem. Biophys. Res. Commun. 337:1-13.

Samani A.A., Yakar S., Leroith D. \& Brodt P. 2007. The role of the IGF system in cancer growth and metastasis: Overview and recent insights. Endocrine Reviews 28:20-47.

Scase T.J., Edwards D., Miller J., Henley W., Smith K., Blunden A. \& Murphy S. 2006. Canine mast cell tumors: Correlation of apoptosis and proliferation markers with prognosis. J. Vet. Intern. Med. 20:151-158.

Scott D.W., Miller W.H. \& Griffin C.E. 2001. Structure and functions of the skin, p.1-70. In: Müller G.H. (Ed.), Small Animal Dermatology. $6^{\text {th }}$ ed. W.B. Saunders, Philadelphia.

Stoop H., Honecker F., Van De Geijn G.J.M., Gillis A.J.M., Cools M.C., De Boer M ., Bokemeyer C., Wolffenbuttel K.P., Drop S.L.S., De Krijger R.R., Dennis N., Summersgill B., McIntyre A., Shipley J., Oosterhuis J.W. \& Looijenga L.H.J. 2008. Stem cell factor as a novel diagnostic marker for early malignant germ cells. J. Pathol. 216:43-54.

Sutter N.B., Bustamante C.D., Chase K., Gray M.M., Zhao K., Zhu L., Padhukasahasram B., Karlins E., Davis S., Jones P.G., Quignon P., Johnson G.S., Parker H.G., Fretwell N., Mosher N.S., Lawler D.F., Satyaraj E., Nordborg M., Lark K.G., Wayne R.K. \& Ostrander E.A. 2007. A single IGF1 allele is a major determinant of small size in dogs. Science 316:112-115.

Takeuchi Y., Fujino Y., Watanabe M., Nakagawa T., Ohno K., Sasakic N., Sugano S. \& Hajime T. 2010. Aberrant autophosphorylation of c-Kit receptor in canine mast cell tumor cell lines. Vet. Immunol. Immunopatol. 137:208-216.

Thamm D.H. \& Vail D.M. 2007. Mast cell tumors, p.402-424. In: Withrow S.J. \& Vail D.M. (Eds), Small Animal Clinical Oncology. $4^{\text {th }}$ ed. W.B. Saunders, Philadelphia.

Thompson J.J., Pearl D.L., Yager J.A., Best S.J., Coomber B.L. \& Foster R.A. 2011. Canine subcutaneous mast cell tumor: Characterization and prognostic indices. Vet. Pathol. 48:156-168.

Villamil J.A., Henry C.J., Bryan J.N., Ellersieck M., Shultz L., Tyler J.W. \& Hahn A.W. 2011. Identification of the most common cutaneous neoplasms in dogs and evaluation of the breed and age distribuitions for selected neoplasms. J. Am. Vet. Med. Assoc. 239(7):960-965.

Webster J.D., Kiupel M., Kaneene J.B., Miller R. \& Yuzbasiyan-Gurkan V. 2004. The use of KIT and tryptase expression patterns as prognostic tools for canine cutaneous mast cell tumors. Vet. Pathol. 41:371-377.

Webster J.D., Yuzbasiyan-Gurkan V., Kaneene J.B., Miller R., Resau J.H. \& Kiupel M. 2006. The role of c-KIT in tumorigenesis: evaluation in canine cutaneous mast cell tumors. Neoplasia 8:104-111.

Webster J.D., Yuzbasiyan-Gurkan V., Miller R.A., Kaneene J.B. \& Kiupel M. 2007. Cellular proliferation in canine cutaneous mast cell tumors: associations with c-KIT and its role in prognostication. Vet. Pathol. 44:298308.

Webster J.D., Yuzbasiyan-Gurkan V., Thamm D.H., Hamilton E. \& Kiupel M. 2008. Evaluation of prognostic markers for canine mast cell tumors treated with vinblastine and prednisone. BMC Vet. Res. 4:32.

Welle M.M., Bley C.R., Howard J. \& Rüfenacht S. 2008. Canine mast cell tumours: A review of the pathogenesis, clinical features, pathology and treatment. Vet. Dermatol. 19: 321-339.

Werner H. 2011. Tumor suppressors govern insulin-like growth factor signaling pathways: implications in metabolism and cancer. Oncogene. Disponível em <http://www.nature.com/onc/journal/vaop/ncurrent/ full/onc2011447a.html>

White C.R., Hohenhaus A.E., Kelsey J. \& Procter-Gray E. 2011. Cutaneous mast cell tumors: association with spay/neuter status, breed, body size, and phylogenetic cluster. J. Am. Anim. Hosp. Assoc. 47:210-216.

Yakar S., Liu J., Stannard B., Butler A., Accili D., Sauer B. \& Leroith D. 1999. Normal growth and development in the absence of hepatic insulin-like growth factor I. Proc. Natl Acad. Sci. USA, Developmental Biology 96:7234-7239.

Yee D. \& Wood T.L. 2008. The IGF system in mammary development and breast cancer. J. Mammary Gland Biology and Neoplasia 13:351-352. 